\title{
NIETZSCHE, O INTEMPESTIVO: SOBRE OS EXCESSOS DA HISTÓRIA CIENTÍFICA E O NÃO-HISTÓRICO
}

\author{
Raylane Marques Sousa ${ }^{1}$ \\ Eduardo F. Chagas ${ }^{2}$
}

\begin{abstract}
Resumo
Nietzsche critica os excessos da história, mas, ao mesmo tempo, defende que a vida tem necessidade dos seus serviços. O que dizer sobre aquilo que é, ao mesmo tempo, prejudicial à vida, um entrave para seu desenvolvimento e a grande conquista dos modernos? Devemos compreender esta ambiguidade a partir dos excessos da própria história ou da sua utilidade enquanto saber não-histórico para a vida? Para respondermos a essas questões, o presente artigo investigará a relação pertinente entre a história cujo saber resulta de uma elaboração científica e a história não-histórica, que pode ser entendida como não-historiográfica e suas exigências.
\end{abstract}

Palavras-chave: Nietzsche. História científica. História não-histórica/nãohistoriográfica.

\section{NIETZSCHE, THE INTEMPESTIVE: ON THE EXCESSES OF SCIENTIFIC HISTORY AND THE NON- HISTORICAL}

\begin{abstract}
Nietzsche criticizes the excesses of history, but at the same time he argues that life needs its services. What to say then about something that is harmful to life, i.e., an obstacle to its development, and at the same time the great achievement of the moderns? Should we understand this ambiguity from the excesses of history itself or from its usefulness as non-historical knowledge directed towards life? In order to answer these questions, the present article will investigate the pertinent relationship between the history whose knowledge results from a scientific elaboration and a non-historical history, which may be understood as a non-historiographical history devoid of history's requirements.
\end{abstract}

Keywords: Nietzsche. Scientific history. Non-historical/non-historiographical history.

\footnotetext{
${ }^{1}$ Mestre em História pela Faculdade de Filosofia e Ciências Humanas da Universidade Federal de Minas Gerais (Fafich/UFMG). Endereço eletrônico: marques.raylane@gmail.com.

${ }^{2}$ Doutor em Filosofia pela Universidade de Kassel, Alemanha. Professor (Associado IV) da Graduação e Pós-Graduação do Departamento de Filosofia da Universidade Federal do Ceará (UFC) e Colaborador do Programa de Pós-Graduação em Educação Brasileira da Faculdade de Educação da Universidade Federal do Ceará (Faced/UFC). Bolsista de Produtividade em Pesquisa do CNPq. Endereço eletrônico: ef.chagas@uol.com.br. Homepage: www.efchagas.wordpress.com.
} 


\section{Introdução}

Como uma estrada perigosa, este artigo é cheio de sinuosidades. Poderíamos apenas expor o assunto a que nos propomos apresentar, se não tivéssemos notado, em nossa investigação da II Consideração Intempestiva (1874), certa ambiguidade, ao menos aparente, no discurso de Nietzsche sobre a história.

Exporemos a ambiguidade, antes mesmo de examiná-la. É útil recordarmos que o alvo de Nietzsche não é o método histórico-crítico, a historiografia propriamente dita, mas a cultura histórica que triunfou entre os modernos. É, pois, a maneira de lidar com a história da cultura alemã que Nietzsche confronta na modernidade. Tal como um médico preocupado em diagnosticar e curar a doença que acomete seu paciente, Nietzsche está interessado em diagnosticar e salvar da "doença histórica" a cultura alemã. E, para isso, ele sugere que a própria história seja submetida aos efeitos do elemento não-histórico. Nietzsche mesmo afirma: "O excesso de história (ein Ubermasse von Historie) mata o homem" (Nietzsche, 2005, p.75). Somente "o estado absolutamente não-histórico (unhistorisch), anti-histórico (widerhistorisch), não engendra apenas a ação injusta, mas também todo ato de justiça" (Nietzsche, 2005, p.76). No entanto, ele também confessa: "Mas se é verdade, como vamos demonstrar depois, que um excesso de conhecimento histórico prejudica os seres vivos, é também absolutamente necessário compreender que a vida tem necessidade do serviço da história" (Nietzsche, 2005, p.82).

Com o problema minimamente exposto, duas questões antes de entrarmos no cerne da interpretação: como fazer com que a história enquanto saber científico regule seus excessos e se converta em um saber não-histórico ou não-historiográfico útil à vida e quais suas exigências? Essas questões são difíceis de responder e permanecem em aberto no ensaio de Nietzsche. No entanto, arriscamos algumas respostas, limitando-nos a discernir as falhas da história científica pelas quais os abusos podem se insinuar nos usos, e a correção feita dos excessos de tal saber que pode sugerir uma história nãohistórica ou não-historiográfica. Em outras palavras, em nossa interpretação, seguiremos, portanto, uma linha de raciocínio que tenta compreender como a história resvalou dos seus usos na modernidade para os abusos, e, ao contrário, como ela regulou os abusos e passou a ser útil para a vida e quais as suas exigências para evitar que se caia nos excessos do primeiro ponto de vista.

\begin{tabular}{|l|l|l|l|l|}
\hline Q Rovista Dialectus & Ano 4 & n. 10 & Janeiro - Julho 2017 & p. 232-247 \\
\hline
\end{tabular}


Como referência de nossa discussão, embora seja uma referência oculta ao longo deste artigo, podemos assumir a contribuição dada por Paul Ricoeur ao debate a respeito da história enquanto saber não-histórico ou não-historiográfico na II Consideração Intempestiva (1874), de Nietzsche. Segundo Ricoeur, essa obra é declarada intempestiva (Unzeitgemässe), inatual, à medida que oferece, diante dos incômodos de uma cultura maciçamente histórica, uma saída para os abusos da história científica entre os modernos, qual seja, colocá-la sob a proteção da bruma a-histórica. Para o autor, a força principal desse texto de Nietzsche está justamente em evocar o elemento a-histórico e o elemento supra-histórico como medicamentos capazes de salvar a cultura histórica dos danos da história científica (Ricoeur, 2007).

Isso posto, para conseguirmos trazer à luz nossos intentos, nos próximos pontos, discutiremos sobre os excessos da história científica que Nietzsche identifica na cultura histórica alemã e, ao mesmo tempo, a importância da história enquanto saber nãohistórico ou não-historiográfico para a vida e suas exigências. Na sequência, abordaremos um argumento que estrutura todo o nosso artigo, qual seja, o de que Nietzsche é um pensador intempestivo.

Neste artigo, propomos ilustrar a ambiguidade do discurso de Nietzsche sobre a história mediante a abordagem das virtudes e dos vícios das três noções de história e da terapêutica que ele propõe a partir da utilização dos elementos a-histórico e suprahistórico, enfatizando a relação da história científica com o elemento a-histórico e suas exigências. Ocupar-nos-emos, principalmente, das análises de Nietzsche em sua II Consideração Intempestiva (1874). Como veremos, é nesse ensaio crítico que nosso autor apresenta a sua mais longa reflexão sobre os excessos da história na modernidade.

\section{Sobre os Excessos da História Científica}

A II Consideração Intempestiva, cujo subtítulo é "Sobre a utilidade e os inconvenientes da história para a vida", obra publicada em 1874 por Nietzsche, então titular da cátedra de filosofia clássica da Universidade de Basileia, contribuiu para expor os excessos da história científica e mostrar particularmente sua aversão à pretensão da escola histórica alemã de tornar a história um saber acadêmico e uma disciplina autônoma. Em oposição a esse tipo de história e a uma cultura maciçamente histórica, Nietzsche enfatiza, portanto, uma abordagem da história submetida ao elemento nãohistórico.

\begin{tabular}{|l|l|l|l|l|}
\hline Q Rovista Dialectus & Ano 4 & n. 10 & Janeiro - Julho 2017 & p. 232-247 \\
\hline
\end{tabular}


Nietzsche procura conscientizar seus contemporâneos dos problemas causados pelos excessos de história científica e que os impede de se desenvolver. Longe de ser um defensor da memória, Nietzsche sempre prescreve o esquecimento para a cura da "doença histórica":

Toda ação exige esquecimento, assim como toda vida orgânica exige não somente a luz, mas também a escuridão. Um homem que quisesse sentir as coisas de maneira absoluta e exclusivamente histórica seria semelhante aquele que fosse obrigado a se privar do sono, ou a um animal que só pudesse viver ruminando continuamente os mesmos alimentos. É, portanto, possível viver, e mesmo ser feliz, quase sem qualquer lembrança, como o demonstra o animal; mas é absolutamente impossível viver sem esquecimento (Nietzsche, 2005, p.72-73).

Para Nietzsche, o homem moderno, preso pelos grilhões do passado, assemelhase a um animal condenado a ruminar continuamente os mesmos alimentos e incapaz de conceber algo novo. Nietzsche faz essa comparação provocadora entre o esquecimento do bovídeo que vive de maneira a-histórica e o homem da memória e da história com intenção de pôr à vista a necessidade do homem que vive inteiramente absorvido pelo sentido histórico. Segundo Nietzsche, o animal de rebanho não consegue distinguir entre o ontem e o hoje, ele pula, alimenta-se, repousa, rumina o que ingere, sente felicidade, prazer e dor, apenas no instante, e assim ele vive os seus dias. Ele é um ser vivo inteiramente desprovido de sentido histórico e seu horizonte se restringe a uma só posição. Ele está privado, portanto, de sentir consternação pelo seu presente, de sentir desolação diante de algo que aconteceu e de sentir desesperança ante o futuro.

O homem moderno, por sua vez, em virtude de sua humanidade está acima do animal, mas, ao mesmo tempo, sente inveja dele, pela sua felicidade plena. Ele é um ser vivo completamente mergulhado no sentido histórico e as linhas de seu horizonte se demovem sem parar. Nesse sentido, tudo o que ele mais deseja é ser como o animal, não conhecer a dor e nem a tristeza, lembrar-se de algo e logo esquecê-lo, viver integralmente absorvido pelo presente, isto é, viver sem apreender a sucessão e a multiplicidade dos instantes e sem guardar na memória reflexos desses instantes. $\mathrm{O}$ animal de rebanho, segundo Nietzsche, está absolutamente imerso no presente; o homem moderno, pelo contrário, está inexoravelmente preso ao passado e é incapaz de esquecê-lo. Para onde ele se desloca, as correntes do passado o seguem, impossibilitando, assim, a sua caminhada independente, os seus passos livres.

\begin{tabular}{|l|l|l|l|l|}
\hline Govista 2 Dialectus & Ano 4 & n. 10 & Janeiro - Julho 2017 & p. 232-247 \\
\hline
\end{tabular}


Segundo Anna Hartmann, durante a elaboração da II Consideração Extemporânea (1874), foi determinante para Nietzsche a leitura do capítulo "Sobre história", que integra o segundo volume da obra $O$ mundo como vontade e como representação, de Arthur Schopenhauer. No dito capítulo, Schopenhauer reflete sobre a atividade da memória e estabelece uma contraposição entre o homem e o animal. Schopenhauer entende o homem como estando hierarquicamente acima do animal, em razão de sua memória e de não se limitar ao restrito presente intuitivo, ao produzir cultura, a linguagem, a escrita e os grandes monumentos, para servirem de memória para a posteridade tardia. Já o animal, ao contrário, está limitado ao estreito presente intuitivo, não pode conhecer a sua própria história, não pode se referir ao passado, não pode explicar o presente e tampouco planejar o futuro. Diante disso, o homem deve se orgulhar ao observar o animal, pois, ao contrário deste ele pode conhecer a sua própria história, ele pode se referir ao passado, que é muito amplo, entender o presente, vislumbrar o futuro, e pode vencer o tempo e o esquecimento (Schopenhauer, 2015).

No que diz respeito à memória, Nietzsche pensa de maneira diferente de Schopenhauer. Para Nietzsche, a memória provoca no homem moderno, o homem do conhecimento histórico, o desejo insaciável pelo passado, impedindo-o de esquecer e de viver o presente. Nietzsche, ao contrário de Schopenhauer, aproxima o homem do animal e afirma que ele sente inveja do animal, pois este vive circunscrito ao instante, livre de sofrimento e de dores, inteiramente alheio ao tempo. Nietzsche pensa sobre a memória não em relação à produção de cultura, como entende Schopenhauer, mas em sua relação com o excesso de história na modernidade (Cavalcanti, 2012).

De igual modo, o homem moderno se sensibiliza ao ver a felicidade da criança, que brinca alegre e inocentemente no presente, sem fazer distinção entre o passado e o futuro. A criança está absolutamente absorvida pelo instante e o seu horizonte se circunscreve a um só momento. Ela não tem ainda um passado para abandonar, esquecer, negar. Entretanto, a criança tem a sua brincadeira interrompida e ela é forçada a assimilar o sentido da palavra "era" (es war), que no discurso de Nietzsche significa "a fórmula que liga o homem aos combates, ao sofrimento e ao desprezo, e o faz lembrar que no fundo toda a existência é tão somente uma eterna incompletude" (Nietzsche, 2005, p.71).

Para Nietzsche, somente a morte cessa os combates, põe fim a inquietude humana e traz o esquecimento tão almejado. Mas, ao mesmo tempo em que traz

\begin{tabular}{|l|l|l|l|l|}
\hline Q Rovista Dialectus & Ano 4 & n. 10 & Janeiro - Julho 2017 & p. 232-247 \\
\hline
\end{tabular}


descanso à alma sôfrega do homem moderno, a morte anula radicalmente o presente e a vida. Não é o decesso, o aniquilamento, o perecimento, portanto, a solução que Nietzsche aponta para o homem que sofre com a "enfermidade histórica". O remédio que cura a afecção do homem do conhecimento histórico é exercitar a "faculdade de esquecer", exigida por qualquer ação, a própria força que ajudará o homem da memória e da história a "desenvolver-se de maneira original e independente, transformar e assimilar coisas passadas ou estrangeiras, curar suas feridas, reparar suas perdas, reconstituir por si próprio as formas quebradas" (Nietzsche, 2005, p.73).

Sem considerar mais importante um determinado tipo de conhecimento histórico em detrimento de outro, Nietzsche menciona três formas de conhecer o passado: a história monumental, a história tradicionalista e a história crítica. Se ele deu maior ênfase ao modo crítico de avaliar o passado, não é possível afirmar com precisão, no entanto, julga que cada um desses três modos de investigar o passado serve ora como remédio, ora como veneno, e defende o justo modo de aplicação de cada uma dessas três formas, denunciando o uso excessivo, em seu tempo, dos modos monumental e antiquado de entender o passado.

Assim, a primeira das três categorias de história, a história monumental, não pode ser entendida pelo excesso, mas sim pela utilidade que ela tem para o homem do presente ao disponibilizar "modelos a serem imitados e superados" (Nietzsche, 2005, p.83) e tornar possível “a perpetuação da grandeza” (Nietzsche, 2005, p.84). É por enfatizar desmedidamente a grandeza que essa forma de história se torna um problema: ela acaba utilizando abusivamente as analogias que fazem com que o passado se ressinta e "segmentos inteiros deste passado sejam esquecidos, desprezados, e escoam num fluxo cinzento e uniforme, de onde somente alguns fatos mascarados emergem como ilhas isoladas" (Nietzsche, 2005, p.88). É nesse sentido que ela se torna um entrave para o passado. E, da mesma forma, ela se torna um veneno para o presente: a admiração pelos grandes e poderosos do passado dissimula e encobre o ódio pelos grandes e poderosos do presente.

A segunda categoria de história, a história tradicionalista, também traz esse problema quanto à utilidade para a vida: conservar e venerar costumes e tradições são atitudes importantes para a vida, mas até determinado ponto: é certo que sem raízes não é possível haver flores e frutos, mas, mais uma vez, o passado sofre com isso, porque todas as coisas passadas são avaliadas a partir da mesma escala de valores e por isso são

\begin{tabular}{|l|l|l|l|l|}
\hline Q Rovista Dialectus & Ano 4 & n. 10 & Janeiro - Julho 2017 & p. 232-247 \\
\hline
\end{tabular}


dignas de serem guardadas e veneradas, e "tudo aquilo que é novo e em vias de nascer acaba, se encontra aí rejeitado e atacado" (Nietzsche, 2005, p.94). Esse tipo de história só sabe conservar, não produzir algo novo.

Quanto à terceira categoria de história, a história crítica, ela não está contaminada pelo historicismo. É apenas um momento, aquele em que a justiça exercita seu severo interrogatório e pronuncia seu veredito implacável, na medida em que "todo o passado merece ser condenado" (Nietzsche, 2005, p.96). Nesse sentido, a história crítica abre espaço para o esquecimento merecido. Esse tipo de história também oferece algum perigo para a vida a partir do momento em que julga e condena todo o passado.

Para Nietzsche, essas três formas de história são, portanto, incontestavelmente úteis à vida. O que importa saber é em que medida se deve imitar a grandeza do passado, venerar as tradições passadas e exercitar o julgamento. Nietzsche não deixou claro as vantagens e os inconvenientes dessas três formas de história, mas enfatizou os problemas que o excesso dessas formas de história pode causar à vida. Estabelecer a própria medida dessas formas de história é um problema que permanece em aberto no ensaio nietzschiano.

Ora, segundo Nietzsche, a história, a partir do momento em que se tornou uma ciência e passou a exigir prioritariamente a verdade dos fatos, ela deixou de ser um saber útil à vida. Nesse sentido, Nietzsche afirma: "Certamente um tal astro, um astro luminoso e soberbo se interpôs [entre a história e a vida], a constelação efetivamente se alterou - pela ciência, pela exigência de que a história seja uma ciência" (Nietzsche, 2005, p.99, grifos do autor). Para Nietzsche, a profissionalização da história desencadeou dois problemas distintos, mas que estão interligados. $\mathrm{O}$ primeiro é que a história científica é um saber paralisador: não existe distinção entre fatos que importam e aqueles que não importam reter, todas as perspectivas apontam infinitamente para trás, para o que já foi, presente e passado são como que a mesma coisa. E os mortos sufocam e enterram os vivos (Binoche, 2014).

O segundo é a formação de uma pseudocultura em oposição à verdadeira cultura alemã: Nietzsche faz ver que, depois da Guerra Franco-Prussiana e Unificação Alemã (1870-1871), dois tipos de cultura entram em disputa na Alemanha. Ao contrário do que imaginamos, o embate não ocorre entre a cultura alemã e a francesa, mas entre a cultura autêntica e a pseudocultura que passou a vigorar no país. Os alemães confundiram cultura e êxito militar e passaram então a acreditar que eram superiores culturalmente

\begin{tabular}{|l|l|l|l|l|}
\hline Q Rovista Dialectus & Ano 4 & n. 10 & Janeiro - Julho 2017 & p. 232-247 \\
\hline
\end{tabular}


(Marton, 2014). Nietzsche quer, portanto, destruir a pseudocultura, a cultura utilitarista, erudita, que afirma o conhecimento histórico científico e está distanciada da ação e da vida prática, e construir, assim, a verdadeira cultura alemã, que não faz oposição entre conhecimento e vida. Este ponto apenas confirma a questão principal que Nietzsche aborda na II Consideração Intempestiva (1874) e de que tratamos neste artigo, qual seja, os problemas desencadeados pelo excesso de história científica.

A começar pela II Consideração Intempestiva (1874), Nietzsche vai se esforçar por demonstrar que o problema da história na modernidade está no método científico de busca e apreensão da verdade dos fatos, que não aceita instâncias, intermediários entre o conhecimento e a sua aplicação na prática. Ele critica o método científico da ciência positivista porque, segundo ele, tal método é responsável pela cisão entre o conhecimento e a vida, isto é, entre o fato, puramente objetivo, comprovável cientificamente, e o sujeito do conhecimento, a subjetividade humana, a interioridade daquele que conhece. Essa oposição de Nietzsche ao conhecimento histórico científico, do tipo negador da vida, o impulsiona a definir uma nova forma de conhecimento histórico, além de um novo método histórico que não busca a essência imutável de todas as coisas e não faz oposição entre conhecimento e vida. Trata-se de uma abordagem da história submetida ao elemento não-histórico. Seria uma história não-histórica ou nãohistoriográfica, da qual falaremos mais adiante.

\section{O Histórico e o A-histórico}

Este é exatamente o princípio sobre o qual Nietzsche nos convoca a refletir: "o elemento histórico e o elemento a-histórico são igualmente necessários para a saúde de um indivíduo, de um povo, de uma cultura" (Nietzsche, 2005, p.74).

Em seu discurso, Nietzsche declara algo diferente do que até então ele vem defendendo. Segundo o filósofo, ao contrário do que somos tentados a pensar, o indivíduo, o povo e a cultura necessitam igualmente dos três elementos para se desenvolverem: do elemento histórico (do sentido histórico), do elemento a-histórico (da atmosfera ou bruma a-histórica) e do elemento supra-histórico. Não é apenas o elemento histórico, como pensam os seus contemporâneos, que cria um ambiente favorável ao desenvolvimento da vida. Também não são somente os elementos ahistórico e supra-histórico que permitem o florescimento da vida. Os três elementos, em justa medida, tornam o ambiente propício à vida. Entretanto, em decorrência da "febre

\begin{tabular}{|l|l|l|l|l|}
\hline Q Ronista Dialectus & Ano 4 & n. 10 & Janeiro - Julho 2017 & p. 232-247 \\
\hline
\end{tabular}


historicista" que ataca os modernos, Nietzsche dá maior enfoque aos benefícios da ausência de sentido histórico, como sendo a falta desse uma espécie de invólucro protetor da vida, sem o qual ela não pode nem brotar nem se preservar.

Com efeito, segundo Nietzsche, o que há de prejudicial no excesso de sentido histórico na modernidade é o perigo de desenraizar o futuro em detrimento de uma fixação pelo passado. Quando o sentido histórico impera ilimitadamente, ele solapa as esperanças, então representadas na arte e na religião, e proíbe as coisas existentes de estarem resguardadas sob o único véu em que elas podem manter-se vivas. Assim, Nietzsche garante, para evitar a "doença histórica" são necessários dois remédios, dois antídotos contra o veneno da história, quais sejam: a força a-histórica e a força suprahistórica. O primeiro impulso, Nietzsche caracteriza como sendo a faculdade de esquecer e de se resguardar num horizonte limitado; já o segundo impulso, o filósofo qualifica como aquele que faz mover o olhar do devir e o direciona para o que dá à vida um caráter de imortalidade e de imutabilidade, isto é, para a arte e a religião (Nietzsche, 2005).

De acordo com Nietzsche, a força ou atmosfera a-histórica pode ser mais bem entendida por meio do exemplo do habitante do vale alpino. Os habitantes do vale alpino vivem fechados em um horizonte, possuem suas tradições e costumes próprios e se orgulham de ter tais tradições, doutrinas e costumes. Nesse sentido, em relação aos habitantes de outros lugares, na maioria das vezes, os habitantes do vale alpino erram e são injustos em seus julgamentos, uma vez que eles têm como referências apenas aquilo que está circunscrito em seu horizonte. Viver restrito em um horizonte dá-lhes, no entanto, a sensação de serem únicos, pois que não dividem a sua história com outros povos, os seus feitos com outros habitantes, e isso é para eles sinal de saúde e vigor invejáveis. O mesmo ocorre com um indivíduo tomado por uma violenta paixão, seja por uma mulher ou algo diferente, pois isso o leva a enxergar o mundo de uma nova maneira: mais próximo, mais concreto, mais colorido, mais audível. O homem apaixonado tem seu julgamento de valores modificado e invalidado: o que antes era importante agora não é mais, o que antes não tinha sentido passa a ter valor, pois o seu horizonte de visão se abre e ele enxerga as coisas a partir de um novo campo de visão.

O que se apresenta como fundamental da força a-histórica é que ela cria a ilusão como uma atmosfera protetora. É como um esquecimento ativo que permite entender, selecionar, recortar, rearranjar elementos do passado no presente a partir de uma linha

\begin{tabular}{|l|l|l|l|l|}
\hline Q Rovista Dialectus & Ano 4 & n. 10 & Janeiro - Julho 2017 & p. 232-247 \\
\hline
\end{tabular}


delimitadora que separa o que deve ser lembrado e o que deve ser ignorado. Tanto o habitante do vale alpino quanto o indivíduo apaixonado criam em torno de si um véu de ilusão, seleciona de maneira diferente os elementos de sua realidade, deixando de lado o habitual e acomodando novos elementos (Cavalcanti, 2012).

A atividade desempenhada pelo habitante do vale alpino e pelo homem apaixonado, os quais veem tudo a partir da perspectiva a-histórica é diferente, por exemplo, do trabalho desempenhado pelo estudante de história, que vê tudo a partir do ponto de vista histórico e, por isso, é obrigado a reproduzir um conhecimento já dado, como veremos mais adiante. De dentro da perspectiva a-histórica emergem novas formas de interpretação do passado, formas essas que rompem com o contínuo da história e facilitam a entrada para o novo, o que não ocorre com a perspectiva histórica. A relação que Nietzsche estabelece entre o elemento histórico e o elemento a-histórico tem o objetivo de questionar a ênfase dos modernos ao elemento histórico, mostrando que o resultado do excesso de história é desastroso para o indivíduo, para o povo e para a cultura.

Nietzsche distingue o elemento histórico do elemento a-histórico na tentativa de se contrapor à história científica praticada na modernidade. Ele quer, na verdade, propor uma nova história a partir do ponto de vista da vida. Nesse sentido, ele formula um novo problema: não enfatizar mais o que diferencia o elemento histórico do elemento ahistórico, mas o que os liga, considerando os dois elementos como necessários para a vida. O elemento a-histórico forma em torno da história uma bruma protetora, enquanto o elemento histórico limita o a-histórico a partir da reflexão, assim como transforma o passado em algo proveitoso para o presente, na medida em que junta pensamento e vida. Dito de outra maneira, o esquecimento é o elemento a-histórico que permite o homem se desvincular das tradições e dos valores cristalizados, enquanto a memória é o elemento histórico que limita o esquecimento por meio da reflexão, retirando do passado somente o que é valioso para o presente.

\section{O Histórico e o Supra-histórico}

Quanto ao elemento supra-histórico, Nietzsche faz questão de distingui-lo do tipo histórico, e demonstra isso a partir da seguinte indagação: questiona ao homem histórico e ao homem supra-histórico se eles gostariam de reviver os últimos dez ou vinte anos de suas vidas. Ambos responderiam que não, mas por motivos distintos. $\mathrm{O}$

\begin{tabular}{|l|l|l|l|l|}
\hline Q Rovista Dialectus & Ano 4 & n. 10 & Janeiro - Julho 2017 & p. 232-247 \\
\hline
\end{tabular}


homem histórico não gostaria de reviver os últimos dez ou vinte anos de sua vida porque ele acredita que os próximos dias serão melhores. Na concepção de Nietzsche, o homem histórico responde de maneira positiva porque está influenciado pela filosofia hegeliana da história, que acredita cegamente no poder da razão para desvelar o processo histórico, seu sentido, sua meta e sua verdade, e na razão como sentido subjacente a esse processo. O resultado disso é a crença de que o presente é resultado do processo universal, como veremos na próxima seção deste capítulo. A partir da crítica à racionalidade histórica, Nietzsche desenvolve a perspectiva supra-histórica, para avaliar o conhecimento produzido na modernidade (Cavalcanti, 2012).

A perspectiva supra-histórica apoia-se no valor do conhecimento, não busca a verdade da história, como faz o tipo histórico. O homem supra-histórico não quer reviver os últimos dez ou vinte anos de sua vida porque acredita que o mundo está completo e já chegou ao seu termo. Nesse sentido, ele não tem necessidade de reviver tudo o que já passou, pois já aprendeu o que tinha de aprender. A particularidade da perspectiva supra-histórica está justamente em sua relação com a história monumental, da qual falamos na seção anterior deste capítulo. Na história monumental, o homem trava um grande combate e precisa de modelos, mas como não encontra em seu presente, ele se volta para o passado e tenta enxergar nele exemplos que sirvam de modelos para novos combates. Esses modelos são tipos indestrutíveis, isto é, obras, monumentos, grandes feitos, que estão acima do contínuo do tempo, pela sua singularidade e diferenciação. No tipo supra-histórico, passado e presente são um só, e a história monumental, por meio dos exemplos, consegue também estabelecer a identidade entre passado e presente e, dessa maneira, elevar-se acima do contínuo do tempo. Nesse sentido, o elemento supra-histórico aproxima-se do tipo de história exemplar, porque ambos conseguem se sobressair da linha contínua do tempo. No entanto, para que o passado sirva de exemplo para o futuro, ele deve provocar a ação no presente, transformação que produza novos feitos e sirva novamente de exemplo para o futuro. Assim, o passado só serve de modelo para o futuro se ele expressar capacidade de criação, movimento e mudança no presente. Em Nietzsche, o passado não serve simplesmente de imitação para o presente, mas como exemplo para a criação de algo original e singular no presente (Cavalcanti, 2012).

Na perspectiva supra-histórica, a interpretação do passado demanda uma atitude seletiva, não quer reconstruir o passado em sua totalidade, tal como aconteceu, não

\begin{tabular}{|l|l|l|l|l|}
\hline Q Povista Dialectus & Ano 4 & n. 10 & Janeiro - Julho 2017 & p. 232-247 \\
\hline
\end{tabular}


pretende encontrar a verdade da história no contínuo do tempo, mas o seu valor, e isso só é possível a partir da observação dos momentos que podem suscitar a grandeza, a monumentalidade. $\mathrm{O}$ valor da história não significa criar uma continuidade entre os acontecimentos, mas destacar a particularidade entre os eventos que se repetem, tornando-os símbolos, em modelos. O que se deve extrair do passado são os exemplos que "despertam forças", isto é, que servem como modelo artístico para o futuro. Assim, na concepção supra-histórica, Nietzsche une o passado e o presente a partir dos exemplos-monumentos da história, mas isso para produzir um conhecimento que esteja enraizado na vida (Cavalcanti, 2012).

Enquanto a história como concebida na modernidade não tem sentido para aquele que a conhece, pois que é somente injustiça, imitação e ilusão, se ela for submetida à perspectiva supra-histórica, ao ponto de vista da vida, o que implica considerá-la como seleção e hierarquia, ela se torna fonte de reflexão e mudanças para o presente. Nietzsche não quer que os modernos renunciem à história, mas sim à continuidade histórica, à história como ciência e conhecimento puro, como imitação, repetição de valores e tradições cristalizados, para que então seja possível a renovação da cultura e a união entre saber e vida (Cavalcanti, 2012).

\section{A História Científica em Contradição com as Forças A-histórica e Supra-histórica}

Segundo Nietzsche, a ciência moderna entende as forças a-histórica e suprahistórica como potências maléficas, uma vez que estimulam a capacidade do esquecimento e demarcam o horizonte humano. A ciência observa todas as coisas cientificamente, e a única concepção verdadeira e aceitável para ela é a de que as coisas resultam do progresso, do desenvolvimento histórico, da lógica da continuidade histórica, e não de algo que se pressupõe, que já existe. Nesse sentido, a ciência vive em desacordo com as forças perpétuas e imperecíveis da arte e da religião, pois que essas necessitam da ilusão para se efetivarem. Uma religião, seja ela qual for, que queira se tornar em um saber puramente científico, está condenada ao fracasso. Nietzsche aponta, como exemplo trágico, o Cristianismo. Segundo o filósofo, o Cristianismo, à luz da pesquisa histórica, tornou-se uma religião propagadora da desolação e da destruição, porquanto a dissecação histórica o diluiu em uma ciência pura e pragmática do Cristianismo. O que antes é tido como uma ilusão necessária, por causa da exatidão e rudeza da ciência, tornou-se uma doença dolorosa, maligna e, o pior de tudo,

\begin{tabular}{|l|l|l|l|l|}
\hline Q Ponista Dialectus & Ano 4 & n. 10 & Janeiro - Julho 2017 & p. 232-247 \\
\hline
\end{tabular}


contagiosa. O motivo disso é porque, para Nietzsche, o saber científico não permite falsificações e trabalha escrupulosamente para trazer à superfície os erros, os descuidos, as irregularidades, a dureza, que acabam por sufocar e matar a imaginação, indispensável para o desenvolvimento da vida.

Os estudos históricos, da mesma forma, por se tornarem em um saber regulado pela ciência moderna, não aceitam distorções da realidade e, por isso, se tornam ressequidos, artificiais e abusivos. Apenas a partir do momento em que os estudos históricos se transformarem em uma criação artística é que a história poderá reavivar e preservar o seu instinto criador. Para Nietzsche, a inspiração que move o estudante de história, que com antecedência já é induzido a apropriar-se do método que usará em suas pesquisas, é diferente do instinto construtor da arte; o estudioso da história já é instruído para "recortar cuidadosamente do passado um pequeno capítulo, sobre o qual ele empregará a sua sagacidade e o método apreendido" (Nietzsche, 2005, p.135), como também treinado para dizer, soberbamente, que "criou", produziu, tal pesquisa. Diante do espetáculo da história universal, da variedade de culturas e de abordagens, o estudante se dá conta que cada cultura tem suas especificidades, suas singularidades. No entanto, ao passo que ele se apropria do método histórico, ele perde o sentimento de estranheza diante dos fatos passados e passa a considerar a diversidade como parte de sua formação histórica. Dito de outra maneira, o estudante é obrigado a assimilar o conhecimento produzido a partir da história universal. Ele se torna um estudante indiferente, apático, em relação à cultura e aos costumes estudados, e o que ele faz é apenas reproduzir as formas de produção do saber histórico (Nietzsche, 2005).

Nietzsche deixa claro que o historiador dominado pela ciência não tem necessidade de se voltar de forma excessiva e desvairada ao passado, como faziam os antigos; agir dessa forma é, como ele demonstra no que concerne aos seus contemporâneos, assustadoramente perigoso (Nietzsche, 2005). Aqui, parece estar em contradição com relação ao que expomos neste artigo que Nietzsche se volta para o conceito de história dos antigos e dele faz um escudo contra a doença histórica. Nietzsche não nega a sua opção pela história como concebida pelos antigos, quando menos nesse contexto. No caso do trabalho desenvolvido pelo estudante de história, que Nietzsche analisa de maneira específica, ele demonstra uma preocupação diferente do que ele vem esboçando desde o início da II Consideração Extemporânea (1874), qual

\begin{tabular}{|l|l|l|l|l|}
\hline Q Rovista Dialectus & Ano 4 & n. 10 & Janeiro - Julho 2017 & p. 232-247 \\
\hline
\end{tabular}


seja, a de que o historiador, no afã de tudo dissecar por meio do método da ciência moderna, examine o passado e nele se limite.

Nietzsche é enfático também quando se refere ao tratamento dado aos clássicos da música alemã, os quais ele denomina de "gênios" inspiradores da cultura alemã. Importantes músicos, como Mozart e Beethoven, segundo Nietzsche, são duramente submetidos ao crivo da pesquisa histórica, a perguntas lancinantes e inconvenientes, quando interrogados pelo historiador cientista. Para Nietzsche, transformar a vida e a obra de tais músicos em livros, em biografias abertas, em fontes para a pesquisa é um sacrilégio, porquanto expõem, de forma injusta e cruel, simplesmente para alimentar a curiosidade de poucos, as minúcias da vida de tais autores. Nesse sentido, a crítica de Nietzsche ao trabalho do historiador moderno se sustenta no fato de o filósofo achar que os grandes nomes da cultura alemã devem estar protegidos pelo véu nebuloso do mistério, devem estar mergulhados na atmosfera da a-historicidade. Na concepção de Nietzsche, o excesso de sentido histórico e a cultura histórica moderna arrancam dos grandes criadores o véu da a-historicidade e, com isso, privam o historiador do sentimento de estupefação e de maravilhamento face às grandes e poderosas coisas que se apresentam diante dele. Se a arte, o gênio ou a religião são privados do invólucro protetor da a-historicidade, como assevera Nietzsche, não se deve pasmar ao vê-los murchar, minguar e se tornar inférteis.

Segundo Nietzsche, a vida, a arte, o gênio e a religião não podem brotar e se conservar no solo vulcânico e precário da ciência, em razão de não ser um solo saudável, firme, seguro. Somente o terreno constante e eterno das forças a-histórica e supra-histórica poderia fazê-los germinar e se desenvolver. Diante disso, para Nietzsche, a ciência precisa ser vigiada e controlada pelas forças a-histórica e suprahistórica, para evitar que todas as coisas sejam contaminadas pela doença histórica que a própria ciência moderna engendra.

\section{Nietzsche, o Intempestivo}

Em todo o artigo, partimos do princípio que Nietzsche é um pensador intempestivo e do espírito livre. Por que intempestivo e do espírito livre? Intempestivo não é ser "intemporal", não é ser abstraído do tempo presente. O que é, portanto, ser intempestivo? Intempestivo significa não concordar com o "espírito do seu tempo". O pensador intempestivo é aquele que toma certa distância de sua época, tal distância não

\begin{tabular}{|l|l|l|l|l|}
\hline Q Rovista Dialectus & Ano 4 & n. 10 & Janeiro - Julho 2017 & p. 232-247 \\
\hline
\end{tabular}


diz respeito à temporalidade ou à historicidade, mas refere-se apenas ao seu tempo, isto é, à atualidade e aos valores que lhe são próprios (Denat, 2009, p.88). O pensador intempestivo e do espírito livre tem a capacidade de pensar de outro modo, de enxergar a partir de outros ângulos e de se desprender da sua cultura, ele não permanece preso ao que a sua época louva e se orgulha - a cultura, os valores, as conquistas militares. Ele é capaz de estar em sua época e adotar pontos de vista de outras épocas, de outros lugares, de outros povos, de outras culturas, e isso em benefício de um tempo e de uma cultura futura.

Nietzsche critica veementemente a história ciência e exige dos historiadores que façam outro tipo de história, a saber, a história não-histórica ou não-historiográfica; que busquem na Antiguidade clássica o modelo de cultura a ser implantado na modernidade; que pensem o passado não como um tempo acabado, mas como fonte de exemplos para inspiração, condução e aperfeiçoamento do homem no presente; que reflitam sobre o presente de maneira criativa e que olhem para o futuro como um horizonte aberto e como um lugar de surpresas. Todas essas exigências que Nietzsche faz aos historiadores de seu tempo demonstram a intempestividade e a liberdade do seu pensamento. Tudo isso nos leva a concluir que Nietzsche é um filósofo que está em seu tempo, pensando sobre as questões do seu presente, porém contra ele e em benefício de um tempo vindouro.

\section{Referências Bibliográficas}

BINOCHE, Bertrand. Do valor da história à história dos valores. Cadernos Nietzsche, São Paulo, v.1, n. 34, p. 35-62, 2014.

CAVALCANTI, Anna Hartmann. Nietzsche, a memória e a história: reflexões sobre a Segunda Consideração Extemporânea. Philósophos, Goiânia, v.17, n.2, p. 77-105, jun./dez. 2012.

DENAT, Céline. Nietzsche, pensador da história? Do problema do "sentido histórico" à exigência genealógica. In: MARTON, Scarlett (Org.). Nietzsche, um francês entre franceses. São Paulo: Barcarolla, Discurso Editorial, 2009, p. 135-165.

MARTON, Scarlett. Considerações Extemporâneas. Distância e combate: a (in)atualidade do filósofo. In: Nietzsche e a arte de decifrar enigmas - Treze conferências europeias. 1. ed. São Paulo: Edições Loyola, 2014, p. 33-52.

NIETZSCHE, Friedrich. II Consideração Intempestiva: sobre a utilidade e os inconvenientes da História para a vida. In: SOBRINHO, Noéli Correia de Melo. Escritos sobre História. Rio de Janeiro: Ed. PUC-Rio; São Paulo: Loyola, 2005.

\begin{tabular}{|l|l|l|l|l|}
\hline Q Rovista Dialectus & Ano 4 & n. 10 & Janeiro - Julho 2017 & p. 232-247 \\
\hline
\end{tabular}


Obras incompletas. Seleção e ensaio de Gérard Lebrun. Tradução de Rubens Rodrigues Torres Filho. São Paulo: Editora 34, 2014.

RICOEUR, Paul. A memória, a história, o esquecimento. Tradução: Alain François [et al.]. - Campinas, SP: Editora da Unicamp, 2007.

SCHOPENHAUER, Arthur. Sobre história. In: O mundo como vontade e como representação. Segundo tomo: suplemento aos quatro livros do primeiro tomo. Tradução, apresentação, notas e índices de Jair Barboza. 1. ed. São Paulo: Editora Unesp, 2015, p. 527-536.

\begin{tabular}{|l|l|l|l|l|}
\hline Govista Dialectus & Ano 4 & n. 10 & Janeiro - Julho 2017 & p. 232-247 \\
\hline
\end{tabular}

